Hum Genet (1981) 59:39-46

\title{
Familial Factors in Early Deaths: Twins Followed 30 Years to Ages 51-61 in 1978
}

\author{
Zdenek Hrubec $^{1}$ and James V. Neel ${ }^{2}$ \\ ${ }^{1}$ Medical Follow-up Agency, National Academy of Sciences-National Research Council, 2101 Constitution Avenue, Washington, D.C. 20418, USA \\ ${ }^{2}$ Department of Human Genetics, University of Michigan, 1137 E. Catherine Street, Ann Arbor, Michigan 48109, USA
}

Summary. Subjects in the National Academy of SciencesNational Research Council Twin Registry of 31,848 male twin veterans were followed for mortality from 1 January 1946, or from the date of entry into military service if that was later, to 31 December 1978. During this time 3,573 deaths occurred among them, 837 due to trauma and 2,712 due to disease.

Mortality from all causes for the entire follow-up period was $10.2 \%$ among 11,350 monozygotic (MZ) twins and $11.4 \%$ among 14,450 dizygotic (DZ) twins. Mortality of veterans is known to be favorable compared to U.S. males. Among U.S. males of the same ages as the two respective twin zygosity groups, a mortality of $13.9 \%$ would have been expected during this time period. Observed mortality from trauma was $2.3 \%$ for $\mathrm{MZ}$ twins and $2.5 \%$ for $\mathrm{DZ}$ twins, with $3.0 \%$ expected in either group. Observed mortality from all disease was $7.9 \%$ for $\mathrm{MZ}$ twins and $8.8 \%$ for $\mathrm{DZ}$ twins, with $10.9 \%$ expected in either group.

For total mortality, the case twin concordance rates, based on individual deaths, were $28.2 \%$ among $\mathrm{MZ}$ twins and $17.7 \%$ among DZ twins. For trauma, respectively by zygosity, these concordance rates were $6.9 \%$ and $3.9 \%$. In this sample, familial factors appear to be of little consequence in trauma deaths. For all disease the concordance rates were $30.1 \%$ and $17.4 \%$. Estimating heritability of liability to death from disease, as proposed by Edwards (1969), provides values of $h^{2}=r=0.51$ for $\mathrm{MZ}$ twins, $h^{2}=2 r=0.48$ for DZ twins, and $h_{2}=2\left(r_{\mathrm{MZ}}-r_{\mathrm{DZ}}\right)=$ 0.54 using data for the two zygosity groups combined.

\section{Introduction}

There is ample evidence that familial factors affect longevity (Dublin et al. 1949; Wyshak 1978). Life span as determined by mortality from disease among adults provides the most direct and specific measure of aging, and the marked differences in life span between species indicate that it is genetically controlled. However, the mechanisms involved are complex and incompletely understood. The extent to which genetic factors control aging and life span within species, particularly among humans, has been the subject of much interest (Dublin et al. 1949; Finch and Hayflick 1977; Schneider 1978). Studies of mortality among twins can help to evaluate the extent to which familial factors, which may be genetic, affect longevity, and in that sense reflect aging.

Presented in abbreviated form at The Third International Congress of Twin Studies, Jerusalem, Israel, 19 June 1980

Offprint requests to: $\mathrm{Z}$. Hrubec
Rates of concordance for death between twin pair members, differences in ages at death between them, or correlations in these ages reflect the sharing between twins of both genetic and environmental factors. For most of the common diseases that cause death, the annual mortality risk increases sharply with advancing age. This implies that the life span is biologically limited and would not be much extended by eliminating any one or even several death causes (Simms et al. 1959). If genetic factors affect mortality, the upper limit at which they exert influence is in turn related to the length of life. But the degree of their influence may well be different at different ages. Thus, there is reason to evaluate overall mortality, and mortality from disease regardless of cause, among twins followed from a young age.

Some environmental agents have been related to several different causes of death. The importance of many others probably remains unrecognized and several different environmental factors may contribute to the same cause. To the extent that members of twin pairs share environmental factors, the study of their mortality may provide a comprehensive evaluation of the impact of this sharing on mortality.

Trauma deaths are the major contributor to mortality from childhood to middle age. They are clearly the result of environmental causes, but gene-environment interactions may also be involved in them. Thus, an evaluation of trauma mortality among pre-senescent twins is of interest.

Ideally, a twin study would follow a very large cohort of pairs from birth until all died. Observing large numbers is particularly important at young ages when deaths occur rarely. Such an investigation has not been feasible so far. Wyshak (1978) studied one well-defined population with an appreciable number of deceased twins. However, the record linkage mechanisms have been extended into the past to evaluate mortality that already occurred, and where twin zygosity could not be determined. Other studies that approximate the ideal methodology have been carried out in the Scandinavian countries (Kaprio et al. 1978; Kringlen 1978; Cederlof and Lorich 1978; Hauge et al. 1968). Each of the Scandinavian registries starts with male and female twins over much of the age range who were alive at time of registry compilation, all after 1953. These registries exclude at least the first decade of life, and they have accumulated relatively small numbers of person-years of observation during 20-40 years of age. Various analyses of mortality from specific causes have been reported by the Swedish (Cederlof et al. 1970) and the Danish (Harvald and Hauge 1965; Holm et al. 1980) registries, but none of them have dealt with mortality comprehensively. 
The 15,924 subjects in the National Academy of SciencesNational Research Council (NAS-NRC) Twin Registry, reported on here, are a homogeneous group of males born in the period 1917-1927, who have been followed through their twenties to a mean age of 54 years and to 61 years of age among the oldest. Since all were screened through the induction physical examination, like other veterans the group has been selected for health. Independent evaluations have shown that the Registry subjects are very similar on various socioeconomic characterstics to all U.S. male veterans of the same ages (Behrman et al. 1980).

The purpose of this report is to assess familial and perhaps genetic factors in mortality between the ages of 20 and 60 years from all causes, from trauma, and from all disease. The results relate to longevity by extension; factors that contribute to early death appreciably affect average life expectancy. The work also seeks to describe an analytic framework that will be used in subsequent cause-specific analyses.

\section{Materials and Methods}

The sample of this study consists of the NAS-NRC Twin Registry. The methods used to construct this twin panel have been described (Jablon et al. 1967). White male multiple births occurring in the continental United States during 1917 to 1927 were identified by searching birth certificates. Approximately 108,000 certificates were found. These represent about $93 \%$ of all such births estimated from national statistics to have occurred during those years (Hrubec and Neel 1978). Among them there were 15,924 twin pairs with both members having records in the Master Index File of the Veterans Administration (VA) indicating that both twins had served in the military. Because of the years of birth selected, military service was generally during World War II, although some re-entered or remained in service during the Korean period. These 15,924 twin pairs constitute the sample being followed.

The means by which information is compiled for the members of the twin panel have been reported in detail (Hrubec and Neel 1978). Survival status is determined periodically through the computer based Beneficiary Identification and Records Locator Subsystem of the VA. Veterans of periods of military action are eligible for a burial allowance. The VA is notified of about $98 \%$ of the deaths among World War II veterans by relatives or morticians claiming this allowance (Beebe and Simon 1969). Survival of veterans is favorable compared to the U.S. population of the same sex and age (Seltzer and Jablon 1974), probably because some ill individuals have been screened out by the induction physical examination and because, following separation, veterans have a socioeconomic advantage and easier access to medical care than non-veterans (Myers and Pitts 1977).

For twins identified as deceased, VA hard-copy records have been searched for death certificate information. Causes of death have been coded according to the Eighth Revision of the International Classification of Diseases, Adapted (U.S. Department of Health, Education, and Welfare 1968). On the basis of this coding, in the present report, deaths have been classified as being due to trauma or to disease.

Using addresses obtained primarily through VA records, and from the twins themselves for their co-twins, an attempt has been made to contact every member of the panel in order to verify his eligibility, to determine the zygosity of the twin pair, and to obtain information on medical history since separation from servive. Of all the pairs in the panel, 13,486 have been classified by zygosity to date, most by self-reports or self-reports confirmed by fingerprint and anthropometric similarity scores. Assessments of the accuracy of the twins' opinion of their zygosity in this Registry (Hrubec and Neel 1978; Jablon et al. 1967), and by others (Cederlof et al. 1961; Harvald and Hauge 1965; Torgersen 1979), suggest that approximately $95 \%$ of such classifications are correct. We excluded pairs when their opinions conflicted markedly with a classification based on fingerprint and anthropometric similarity scores. This improves the accuracy of classification among those retained. About 800 twin pairs have been very reliably classified by blood typing, regardless of what other information was available for them; and about 1,950 pairs have been classified using only the fingerprint and anthropometric scoring. Overall, 95\% appears to be a reasonable estimate of the frequency of correct classification among the twins who have been classified.

In the Results section we evaluate the effect on the estimates presented there of a $5 \%$ error in the observed classification of zygosity. For simplicity it is assumed that the rate of error is the same for $\mathrm{MZ}$ as for $\mathrm{DZ}$ twins, namely 0.05 , and that misclassification is random. Then for the zygosity indicated by the subscripts, an estimate $m^{\prime}$ is a proportional sum of the correct values $m$ as follows.

$$
\begin{aligned}
& m_{\mathrm{MZ}}^{\prime}=0.95 m_{\mathrm{MZ}}+0.05 m_{\mathrm{DZ}} \\
& m_{\mathrm{DZ}}^{\prime}=0.05 m_{\mathrm{MZ}}+0.95 m_{\mathrm{DZ}}
\end{aligned}
$$

Solving these equations for the two correct values of $m$ gives

$$
\begin{aligned}
& m_{\mathrm{MZ}}=\frac{0.95 m_{\mathrm{MZ}}^{\prime}-0.05 m_{\mathrm{DZ}}^{\prime}}{0.9} \\
& m_{\mathrm{DZ}}=\frac{0.95 m_{\mathrm{DZ}}^{\prime}-0.05 m_{\mathrm{MZ}}^{\prime}}{0.9}
\end{aligned}
$$

These statements are not affected by the actual proportions of $\mathrm{MZ}$ and $\mathrm{DZ}$ pairs.

Among the 31,848 individuals in the panel, altogether 4,583 deaths have been ascertained in midyear of 1979. In order to exclude the World War II period of atypical mortality from this analysis, 1 January 1946 was chosen as the start of the follow-up period, which resulted in the exclusion of 697 deaths in military action, 183 deaths from other trauma, and 46 deaths from disease, all occurring before that date. Also excluded were 56 deaths in military action after 1 January 1946 and three with date and cause of death unknown. There were 27,290 individuals who were alive on 31 December 1978, following which mortality ascertainment is incomplete. The end of December 1978 was, therefore, chosen as the cutoff date for mortality observations, and the 25 subjects identified as deceased after that date have been classified here as alive. Thus, in the period of observation, from the beginning of 1946 to the end of 1978 , there occurred 3,573 deaths not due to military action.

To make a twin pair analysis possible, twin pairs with either member failing to meet the study criteria, i.e., either twin died before 1946, either killed in military action, or either with unknown date of death, have been excluded. The reasons for exclusion and cause of death status of the excluded pairs are shown in Table 1. This selection has resulted in the retention of 29,962 individual subjects observed during the follow-up period, of whom 3,460 died before 1 January 1979. 
Table 1. Number of twin individuals, number of deaths, and percent deceased by status in mortality analysis, and by reason for exclusion

\begin{tabular}{lrrl}
\hline $\begin{array}{l}\text { Status in mortality analysis } \\
\text { and reason for exclusion }\end{array}$ & $\begin{array}{l}\text { Number } \\
\text { of } \\
\text { individuals }\end{array}$ & $\begin{array}{l}\text { Number } \\
\text { of } \\
\text { deaths }\end{array}$ & $\begin{array}{l}\text { Percent } \\
\text { deceased }\end{array}$ \\
\hline Total panel & 31,848 & 4,558 & 14.3 \\
Excluded, total & 1,886 & 1,098 & 58.2 \\
$\quad$ Died before 1946 & 926 & 926 & - \\
Killed in military action $\geq 1946$ & 56 & 56 & - \\
Unknown date of death & 3 & 3 & - \\
Co-twin not eligible & 901 & 113 & 12.5 \\
Included, & & & \\
Both in twin pair eligible & 29,962 & 3,460 & 11.5 \\
$\quad$ Monozygotic & 11,350 & 1,162 & 10.2 \\
$\quad \begin{array}{l}\text { Dizygotic } \\
\text { Unknown }\end{array}$ & 14,450 & 1,646 & 11.4 \\
\hline
\end{tabular}

a Through 31 December 1978 if date is known

Table 2. Number of subjects by age at start of follow-up, ${ }^{a}$ mean age at start, mean years of follow-up, and number of person-years of followup, by zygosity

\begin{tabular}{|c|c|c|c|c|}
\hline \multirow[t]{2}{*}{ Age at start of follow-up } & \multicolumn{4}{|l|}{ Zygosity } \\
\hline & $\begin{array}{l}\text { Mono- } \\
\text { zygotic }\end{array}$ & $\begin{array}{l}\text { Dizy- } \\
\text { gotic }\end{array}$ & $\begin{array}{l}\text { Un- } \\
\text { known }\end{array}$ & Total \\
\hline$<20$ & 2.687 & 3,140 & 1,130 & 6,957 \\
\hline $20-24$ & 5,969 & 7,725 & 2,045 & 15,739 \\
\hline $25-29$ & 2,692 & 3,584 & 986 & 7,262 \\
\hline $30-34$ & 2 & 1 & 1 & 4 \\
\hline Total & 11,350 & 14,450 & 4,162 & 29,962 \\
\hline Mean age at start & 22.13 & 22.27 & 22.02 & 22.18 \\
\hline Mean years of follow-up & 31.52 & 31.38 & 30.54 & 31.32 \\
\hline Number of person-years & 357,793 & 453,480 & 127,127 & 938,400 \\
\hline
\end{tabular}

${ }^{a}$ For $94 \%$ of the subjects, follow-up starts on 1 January 1946. For the $6 \%$ who entered service after that date, it starts on date of entry into service. Excluded have been pairs with either member dying before 1946, in military action, or with date of death unknown

Of the 29,962 eligible subjects, 28,273 entered service before 1946. They have been followed from 1 January 1946, until death, or the cutoff date. The other 1,689 , or $5.6 \%$, who entered service during 1946 through 1955 have been followed from the date of entry. The distribution of start of follow-up year is quite similar for the two zygosity groups. The year of birth distributions for the three groups are also very similar, which leads to the comparable ages at start of follow-up and mean years of followup for these groups, shown by zygosity in Table 2 .

In each zygosity group, the data on individuals were standardized by computing the expected number of deaths among U.S. males of the same ages and for the same calendar time as the twin subjects being followed. The observed numbers of deaths divided by the expected numbers produce Standard Mortality Ratios (SMRs). Age-standardized relative risks, ratios of the SMR for MZ to the SMR for DZ twins, were tested as described by Haldane (1955-1956). The standardization assures that comparisons of $\mathrm{MZ}$ with $\mathrm{DZ}$ twins are not biased by
Table 3. Number surviving first death in pair by age at start of follow-up, mean age, mean number of years of follow-up to death or 31 December 1978 , and total number of person-years, by zygosity

\begin{tabular}{|c|c|c|c|}
\hline \multirow{2}{*}{$\begin{array}{l}\text { Surviving twins, } \\
\text { age at start of follow-up }\end{array}$} & \multicolumn{3}{|c|}{ Zygosity } \\
\hline & $\begin{array}{l}\text { Mono- } \\
\text { zygotic }\end{array}$ & $\begin{array}{l}\text { Dizy- } \\
\text { gotic }\end{array}$ & Total $^{b}$ \\
\hline & \multicolumn{3}{|c|}{ Surviving first death in pair } \\
\hline$<30$ & 94 & 115 & 289 \\
\hline $30-39$ & 126 & 219 & 468 \\
\hline $40-49$ & 393 & 580 & 1,181 \\
\hline $50-54$ & 238 & 378 & 701 \\
\hline $55-6 \mathrm{I}$ & $\underline{145}$ & 204 & 410 \\
\hline Total & 996 & 1,496 & 3,049 \\
\hline Mean age at start & 45.32 & 45.49 & 44.82 \\
\hline Mean years of follow-up & 9.65 & 9.86 & 10.20 \\
\hline Number of person-years & 9,613 & 14,758 & 31,113 \\
\hline
\end{tabular}

${ }^{a}$ Follow-up starts on date of death of co-twin

Includes 557 with unknown zygosity and mean years of 42.13 for starting age and 12.10 for follow-up duration

selective factors that might affect one group more than the other and produce differences in age distributions, mortality schedules, or duration of follow-up at different ages. Veterans in general have lower mortality than U.S. males, but age and calendar-specific mortality rates are not available for them, and a standardization to the veteran population cannot be carried out reliably.

One analysis of twin concordance was carried out by considering a co-twin of a deceased twin at risk of death from the date (and age) at which the first death in the pair occurred until the second death or until the cutoff date. The distribution of ages of twins at the first death in the pair, the start of their follow-up in this analysis, is shown in Table 3. Among the 3,460 deaths that met the criteria listed in Table 1, there are 2,652 single deaths and 404 concordantly deceased pairs. For 397 of them, first and second deaths could be distinguished. The remaining seven pairs with equal dates of death include three $\mathrm{MZ}$ and three $\mathrm{DZ}$ pairs with both deaths due to trauma. The numbers shown in Table 3 provide the means of estimating annual mortality rates in the remainder of the follow-up period among co-twins who survived the first death in the pair. These mortality rates are, in effect, annual pair concordance rates of death as defined below.

The pair concordance rate divides the number of concordant pairs by the number of pairs with one or both twins affected. This rate is to be distinguished from the case concordance rate which is the number of individuals in twin pairs concordant for the causes of death of interest divided by the total number of deaths from those causes. The generally preferred proband concordance rate uses secondarily ascertained cases, found among cotwins of originally ascertained probands, to correct for deficits in the primary ascertainment. It cannot be employed in this study, because ascertainment of mortality is carried out independently for the two members of the twin pair, with no secondary ascertainment of co-twins of probands (Hrubec and Allen 1975).

The definitive analysis of the twin concordance data on mortality to estimate heritability was done using case concordance rates, in a conventional manner as proposed by Edwards (1969). This is much like the method proposed by Falconer 
Table 4. Observed and expected numbers of deaths, corresponding annual mortality per 1,000 person-years, and standard mortality ratios, ${ }^{a}$ by age at follow-up, zygosity, and cause of death

All twins

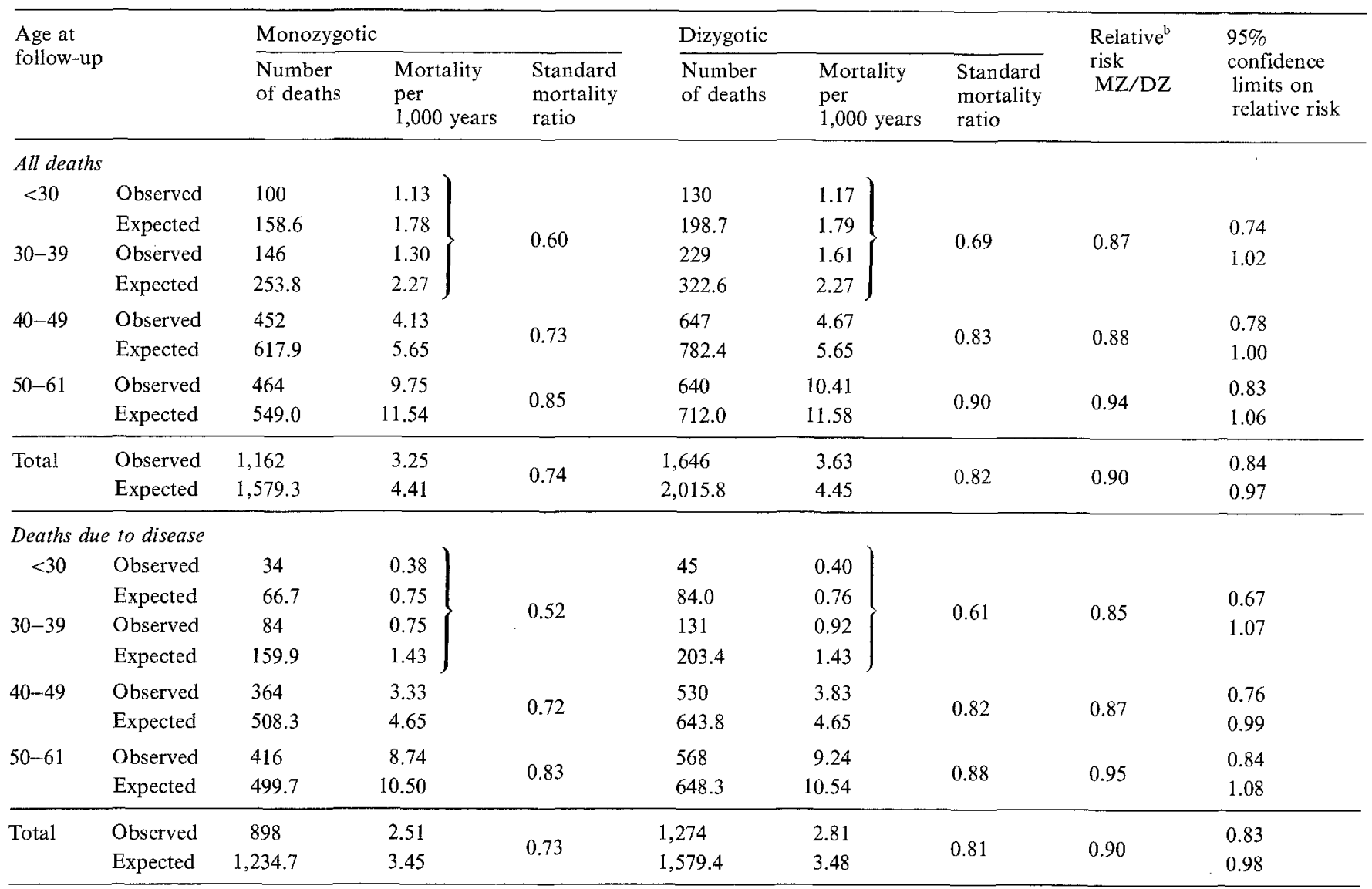

a Observed deaths/expected deaths

b $\mathrm{SMR}_{\mathrm{MZ}} / \mathrm{SMR}_{\mathrm{DZ}}$

(1965) but requires fewer assumptions. The Edwards model is developed from generally accepted principles of genetic analysis (Vogel and Motulsky 1979) by postulating a multifactorial liability to the event of interest which becomes realized when a threshold liability value is exceeded. Subjects with equal dates of death have been included in this analysis. For comparative purposes the index Hć characterized by Allen (1979) as estimating the relative degree of familial determination has also been obtained. Hć is computed as $1-\left(C_{\mathrm{DZ}} \div C_{\mathrm{MZ}}\right)$, where $C$ is the case concordance rate of the subscripted zygosity. Hć is a convenient index of the relative degree of familial determination not dependent on a specific genetic model (Allen 1979).

\section{Results}

The observed and expected numbers of deaths, mortality rates, and SMRs are shown in Table 4 by age at follow-up, when the mortality occurred, and by cause group for $\mathrm{MZ}$ and $\mathrm{DZ}$ twins. In the entire sample, there were 3,460 deaths from start of follow-up to the end of 1978 , and 4,142.6 deaths would have been expected in a comparable U.S. population during this period. This yields an SMR of 0.84 . The SMR for MZ twins is 0.73 , for DZ twins it is 0.81 , and for twins with unknown zygosity it is 0.97 . In all age groups the expected mortality rates among $\mathrm{MZ}$ twins are almost identical to those among DZ twins for all deaths, deaths from disease, and also deaths from trauma, which are not shown. Therefore, standardizing the observed $\mathrm{DZ}$ rates to the $\mathrm{MZ}$ age distribution does not change the observed $\mathrm{DZ}$ rates and the standardized rates are not presented. Mortality rates increase with increasing age, and the SMRs are closer to 1.0 in the oldest age group. The ratio of the respective SMRs for $\mathrm{MZ}$ and $\mathrm{DZ}$ twins provides an age-standardized relative risk of 0.9 for all deaths and also deaths from disease, favoring MZ twins, both of which are statistically significant with $P<0.01$.

An analysis of mortality among survivors of the first death in the pair is shown in Table 5 for MZ and for DZ twins by age at follow-up. In the entire panel, 397 such deaths were observed and 240.5 would have been expected among U.S. males during the time that the survivors were under observation. This yields an SMR of 1.65. The SMRs for all ages, respectively for MZ and DZ twins, are 2.2 and 1.2. As for all twin individuals, so for survivors of the first death in the pair, in each age group the expected mortality rates of $\mathrm{MZ}$ twins are almost equal to those of $\mathrm{DZ}$ twins, and age-standardizing the $D Z$ values to the $M Z$ group does not change the observed $\mathrm{DZ}$ rates. Mortality increases with increasing age. The number of deaths under age 40 is too small for meaningful evaluation of relative risk by age. The relative risk can also be interpreted as an age-standardized ratio of twin pair concordance rates of death. For all ages combined it is 1.8 
Table 5. Observed and expected numbers of deaths, corresponding annual mortality per 1,000 peson-years, and standard mortality ratios, ${ }^{a}$ by age at follow-up, zygosity, and cause of death

Survivors of first death from any cause in pair ${ }^{\mathrm{b}}$

\begin{tabular}{|c|c|c|c|c|c|c|c|c|c|}
\hline $\begin{array}{l}\text { Age at } \\
\text { follow-u }\end{array}$ & & \multicolumn{3}{|c|}{ Monozygotic } & \multicolumn{3}{|l|}{ Dizygotic } & $\begin{array}{l}\text { Relative }^{\mathrm{C}} \\
\text { risk } \\
\mathrm{MZ} / \mathrm{DZ}\end{array}$ & $\begin{array}{l}95 \% \\
\text { confidence } \\
\text { limits on } \\
\text { relative risk }\end{array}$ \\
\hline \multicolumn{10}{|c|}{ All deaths } \\
\hline \multirow[t]{2}{*}{$<30$} & Observed & 2 & 4.55 & \multirow{3}{*}{1.40} & 1 & 1.89 & \multirow{3}{*}{0.49} & \multirow{3}{*}{2.84} & \\
\hline & Expected & 0.8 & 1.70 & & 0.9 & 1.72 & & & 0.77 \\
\hline $30-39$ & Expected & 3.5 & 2.38 & & 5.2 & 2.41 & & & \\
\hline \multirow[t]{2}{*}{$40-49$} & Observed & 47 & 12.09 & \multirow{2}{*}{1.98} & 47 & 7.86 & \multirow{2}{*}{1.29} & \multirow{2}{*}{1.54} & 1.03 \\
\hline & Expected & 23.7 & 6.10 & & 36.4 & 6.09 & & & 2.29 \\
\hline \multirow[t]{2}{*}{$50-61$} & Observed & 109 & 28.68 & \multirow{2}{*}{2.31} & 92 & 15.12 & \multirow{2}{*}{1.22} & \multirow{2}{*}{1.89} & 1.43 \\
\hline & Expected & 47.2 & 12.43 & & 75.4 & 12.39 & & & 2.49 \\
\hline \multirow[t]{2}{*}{$<30$} & Observed & 2 & 4.55 & \multirow{4}{*}{2.31} & 1 & 1.89 & \multirow{4}{*}{0.79} & \multirow{4}{*}{2.92} & \\
\hline & Expected & 0.3 & 0.75 & & 0.4 & 0.78 & & & 0.79 \\
\hline \multirow[t]{2}{*}{$30-39$} & Observed & 4 & 2.69 & & 2 & 0.92 & & & 9.27 \\
\hline & Expected & 2.3 & 1.54 & & 3.4 & 1.56 & & & \\
\hline \multirow[t]{2}{*}{$40-49$} & Observed & 43 & 11.06 & \multirow{2}{*}{2.18} & 42 & 7.02 & \multirow{2}{*}{1.39} & 157 & 1.03 \\
\hline & Expected & 19.7 & 5.07 & & 30.3 & 5.07 & & 1.0 & 2.39 \\
\hline $50-61$ & Observed & 101 & 26.58 & 2.34 & 84 & 13.80 & 1.22 & 1.92 & 1.44 \\
\hline & Expected & 43.2 & 11.38 & 2.04 & 69.0 & 11.34 & 1.22 & 1.52 & 2.56 \\
\hline Total & Observed & 150 & 15.60 & 229 & 129 & 8.74 & 125 & 183 & 1.45 \\
\hline & Expected & 65.6 & 6.82 & 2.29 & 103.1 & 6.99 & $1.2 J$ & 1.03 & 2.31 \\
\hline
\end{tabular}

a Observed deaths/expected deaths

${ }^{b}$ Considered at risk from date of death of co-twin to their own death or to 31 December 1978

- $\mathrm{SMR}_{\mathrm{MZ}} / \mathrm{SMR} \mathrm{DZ}$

Table 6. Percent prevalence, percent casewise twin concordance, and heritability $\left(h^{2}\right) \pm$ standard error by cause and zygosity

\begin{tabular}{|c|c|c|c|c|c|c|c|}
\hline \multirow[t]{2}{*}{ Cause of death } & \multicolumn{3}{|c|}{ Monozygotic } & \multicolumn{3}{|l|}{ Dizygotic } & \multirow{2}{*}{$\begin{array}{l}\text { Combined } \\
\text { heritability } \\
h^{2}=2\left(r_{\mathrm{MZ}}{ }^{-} \mathrm{DZ}\right.\end{array}$} \\
\hline & $\begin{array}{l}\text { Percent } \\
\text { mortality }\end{array}$ & $\begin{array}{l}\text { Percent } \\
\text { concordance }\end{array}$ & $\begin{array}{l}\text { Heritability } \\
h^{2}=r\end{array}$ & $\begin{array}{l}\text { Percent } \\
\text { mortality }\end{array}$ & $\begin{array}{l}\text { Percent } \\
\text { concordance }\end{array}$ & $\begin{array}{l}\text { Heritability } \\
h^{2}=2 r\end{array}$ & \\
\hline Disease & 7.9 & 30.1 & $0.51 \pm 0.03$ & 8.8 & 17.4 & $0.48 \pm 0.06$ & $0.54 \pm 0.09$ \\
\hline Trauma & 2.3 & 6.9 & $0.23 \pm 0.07$ & 2.5 & 3.9 & $0.18 \pm 0.15$ & $0.29 \pm 0.20$ \\
\hline
\end{tabular}

with a $95 \%$ limit of 1.4 to 2.2 . Only in the last two age groups and for all ages combined are there sufficient observations to show that the excess risk of $\mathrm{MZ}$ twins is statistically significant with $P<0.05$ for ages $40-49$ and $P<0.001$ for ages 50-61 and for all ages combined. Essentially the same relationships can be seen for deaths from disease as for all deaths, and the results of significance tests are the same.

Among the 3,460 deaths in the total sample, 808 occurred in pairs with both twins deceased, which produces a case concordance rate for deaths from all causes of $23.4 \%$. There were 164 death concordant pairs among $\mathrm{MZ}$ and 146 among DZ twins. These lead to the respective concordance rates, shown in Table 6 , of $28.2 \%$ and $17.7 \%$ and $h^{2}$ values of 0.42 and 0.35 in the two zygosity groups. Whien corrected for the assumed 5\% zygosity misclassification the two concordance rates are, respectively by zygosity, $28.8 \%$ and $17.1 \%$ and the corresponding $h^{2}$ estimates are 0.43 and 0.31 . Statistical testing of this difference yields $P<0.001$. Likewise, the difference in concordances for disease deaths is significant with $P<0.001$, but for trauma mortality the difference is not significant $(P>0.05)$. Heritability estimates for deaths from disease are about 0.5 , regardless of how estimated, and with or without correction for zygosity misclassification. For deaths from trauma and for all deaths, the $h^{2}$ estimates for the two zygosity groups combined are the highest, followed by estimates for MZ twins. In each case the $h^{2}$ values for all deaths are somewhat below the corresponding $h^{2}$ 
Table 7. Number of concordantly deceased twin pairs, mean age at first and second death, mean difference in age and standard error, and intraclass correlation of ages at death by twin concordance for cause of death and zygosity

\begin{tabular}{|c|c|c|c|c|c|c|}
\hline & \multicolumn{6}{|c|}{ Twin concordance for cause of death } \\
\hline & \multicolumn{2}{|c|}{$\begin{array}{l}\text { Both disease } \\
\text { (zygosity) }\end{array}$} & \multicolumn{2}{|c|}{$\begin{array}{l}\text { Both trauma } \\
\text { (zygosity) }\end{array}$} & \multicolumn{2}{|c|}{$\begin{array}{l}\text { Total }^{\mathrm{a}} \\
\text { (zygosity) }\end{array}$} \\
\hline & $\mathrm{MZ}$ & $\mathrm{DZ}$ & MZ & $\mathrm{DZ}$ & $\mathrm{MZ}$ & $\mathrm{DZ}$ \\
\hline Number of pairs & 135 & 111 & 9 & 7 & 164 & 146 \\
\hline $\begin{array}{l}\text { Mean age at first } \\
\text { death }\end{array}$ & 44.09 & 44.31 & 34.78 & 32.00 & 43.47 & 43.13 \\
\hline $\begin{array}{l}\text { Mean age at second } \\
\text { death }\end{array}$ & 50.62 & 51.22 & 41.67 & 39.43 & 50.31 & 50.42 \\
\hline Mean difference & 6.53 & 6.91 & 6.89 & 7.43 & 6.85 & 7.29 \\
\hline $\begin{array}{l}\text { Standard error of } \\
\text { mean difference }\end{array}$ & 0.51 & 0.53 & 2.94 & 3.72 & 0.48 & 0.51 \\
\hline $\begin{array}{l}\text { Correlation of ages } \\
\text { at death }\end{array}$ & 0.29 & 0.15 & 0.53 & 0.29 & 0.33 & 0.26 \\
\hline
\end{tabular}

${ }^{a}$ Includes $2 \mathrm{MZ}$ and $3 \mathrm{DZ}$ pairs with cause of death unknown

values for deaths from disease. The $h^{2}$ values for deaths from trauma are in turn well below those for the other cause groups. In contrast to $h^{2}$, the values of Hć are 0.37 for total mortality, 0.42 for deaths from disease, and 0.43 for deaths from trauma. When corrected for zygosity misclassification these Hć values are respectively $0.41,0.46$, and 0.48 .

Mean age at death and within-pair differences in these ages reflect the age range over which the cohort is followed. In this study the oldest subject was 62 at the end of observation, and most of the mortality occurred in the last 10 years. Differences between zygosity groups in mean interval between first and second death are not statistically significant $(P>0.05)$ for any of the cause groups and neither are the differences in correlation coefficients of ages at death shown in Table 7. However, among the $135 \mathrm{MZ}$ and $111 \mathrm{DZ}$ twin pairs concordant for disease deaths, the interval between the first and second death is four years or less among $52.6 \%$ of the $\mathrm{MZ}$ group and among $40.5 \%$ of the $\mathrm{DZ}$ group. In contrast, for $19.3 \%$ of MZ pairs the interval is 5-9 years compared to $34.2 \%$ of $\mathrm{DZ}$ pairs with these values. At this time, among concordant deaths, the percent of pairs with one twin surviving the other by 10 years or more is similar in the two zygosity groups.

\section{Discussion}

This report evaluates data on pairs of twin veterans in the NASNRC Twin Registry. The subjects were followed from 1946 through 1978 to determine the prevalence and twin pair concordance of death from disease, from trauma, and from all causes. The analysis assesses the importance of familial factors in this mortality and attempts to estimate the heritability of these events. In 1946, the start of observation for most subjects, the youngest were 19 and the oldest were 29 years old. At the end of 1978 they were between 51 and 61 years old. Thus, almost all of them were followed through the age range of 30-50 years.

In the entire sample $11.5 \%$ died in the follow-up period. In a group of U.S. white males of the same age followed for the same time, expected mortality is $13.8 \%$. This is consistent with previously published reports of lower mortality among veterans than among U.S. males (Seltzer and Jablon 1974). Table 4 showed that, as twins of either zygosity aged, their mortality approached that of U.S. males. Induction into military service tended to screen out some portion of high risk individuals, but the effects of this selection tended to be much reduced after 20 years.

While these twins had a mortality similar to that of other veterans, MZ twins had better survival than $\mathrm{DZ}$ twins. The expected mortality percentages are almost equal between the two zygosity groups, and the difference remains even after standardizing for differences in age distribution and mortality schedules $(P<0.01)$. A biologic interpretation of this difference may not be appropriate, as it too may be due to selective factors. DZ twinning rates differ with age of mother, parity, and, consequently, with socioeconomic factors that in turn may affect mortality (Bulmer 1970).

At the end of the follow-up period, 164 , or $2.9 \%$ of all MZ twin pairs, and 146 , or $2.0 \%$ of all $\mathrm{DZ}$ twin pairs, were concordantly deceased. Both twins died from trauma in only nine $\mathrm{MZ}$ and seven $\mathrm{DZ}$ twin pairs. Although this produces a somewhat higher concordance rate for trauma deaths among $\mathrm{MZ}$ than among $\mathrm{DZ}$ twins, the difference is not statistically significant, and it is clear that twin concordance for death from trauma during the ages covered in this study is rare. Among deaths occurring before 1946, and therefore excluded from this analysis, there are 33 pairs concordantly killed in military action of whom 25 could not be classified by zygosity. In the entire Registry of 15,924 pairs there are $14 \mathrm{MZ}$, eight DZ, and 14 pairs of unknown zygosity known to be concordant for deaths from trauma other than that due to military action. Death from disease in one twin does not affect the risk of trauma in the cotwin in either zygosity group in the follow-up sample and in the entire Registry. This all suggests that neither genetic nor other factors shared between twin pair members account for much trauma mortality after the second decade of life.

The $135 \mathrm{MZ}$ and $111 \mathrm{DZ}$ twin pairs concordant for disease deaths provide, respectively, case concordance rate estimates of $30.1 \%$ and $17.4 \%$, a statistically significant difference $(P<0.001)$. When corrected for the assumed $5 \%$ zygosity misclassification, these rates are, respectively by zygosity, $30.8 \%$ and $16.7 \%$, almost the same as the uncorrected values. Respectively, the uncorrected concordance rates are 3.8 and 2.0 times the corresponding percent mortality from disease. This is strong evidence for the effect of familial factors. At present, this sharing seems to account for less than one quarter of all disease deaths among $\mathrm{MZ}$ and less than one tenth of disease deaths among DZ twins when percent concordance is compared with percent mortality. However, this kind of evaluation is highly time dependent.

An estimate that probably is more stable with time than comparing concordance and mortality rates is provided by the $h^{2}$ estimates in Table 6 based on the multigenic threshold effect model (Edwards 1969). The estimates for DZ twins make allowance for their coefficient of relationship of 0.5 , by multiplying by two the tetrachoric correlation estimate of $r$. If environmental factors are shared to the same extent between $M Z$ and $\mathrm{DZ}$ twin pair members, this calculation artifactually inflates the estimate of $h^{2}$ for $\mathrm{DZ}$ as compared to the estimate for $\mathrm{MZ}$ twins. The effect of such sharing is excluded from the combined estimate of $2\left(r_{\mathrm{MZ}}{ }^{-r} \mathrm{DZ}\right)$ (Smith 1974). Our three estimates of $h^{2}$ are similar to each other. They are in turn similar to the Hć 
estimate, and the DZ concordance rate is moderate. The intermediate values of the three estimates of $h^{2}$, their similarity, and the excess of concordance rates over individual mortality rates all suggest that disease mortality during the ages under study is influenced by both genetic and partly shared environmental factors. The values of $h^{2}$ for $\mathrm{MZ}$ and for $\mathrm{DZ}$ twins estimate the same quantity from two independent samples. If only environmental factors shared between twin pair members were responsible for the within pair concordances noted, it is unlikely that there would be such good agreement between the different measures of genetic effect. Tobacco smoking and alcohol abuse are some of the factors that might be of consequence at these ages.

The results are consistent with a report by Wyshak (1978) on twins born before 1850 and identified in the Archives of the Genealogical Society of the Mormon Church, who survived to adulthood and married, and for whom both birth and death dates were recorded. Although Wyshak cannot classify twins by zygosity, the correlation of ages at death between pair members is $r=0.14$ for 464 male-male pairs $(P<0.01)$ and $r=0.24$ for 216 female-female pairs $(P<0.01)$. Restricting the sample to pairs with both deaths under 60 years of age increases the correlations to $r=0.53$ for 55 male-male pairs and $r=0.31$ for 37 female-female pairs (Wyshak 1981). The values we obtained are $r=0.33$ for $164 \mathrm{MZ}$ and $r=0.26$ for $146 \mathrm{DZ}$ male twins (Table 7 ). The correlations in our sample will probably also become smaller when the Twin Registry subjects reach the end of their life span and their ages at death attain the greatest variance. Both Wyshak's (1981) and our estimates of correlations in ages at early death are similar to the tetrachoric correlations $(r)$ we obtained in estimating the heritability of the liability to death $\left(h^{2}\right)$, namely, $r=0.42$ for $\mathrm{MZ}$ and $r=0.18$ for $\mathrm{DZ}$ twins. Considering the sampling variability of each of these estimates, the results appear quite comparable.

Heritability of the liability to death $\left(h^{2}\right)$ cannot be evaluated using Wyshak's data. However, Jarvik et al. (1960) present data on deaths after age 60 years in pairs with at least one twin reaching age 60 . Their sample was compiled from a variety of sources, including general and psychiatric hospitals and homes for the aged. When only the pairs with both twins alive at age 60 are evaluated, the case concordance rates of death in the following 12 years are $69.3 \%$ for $\mathrm{MZ}$ and $72.4 \%$ for DZ male twins. The resulting estimates of the heritability of liability to death in that 12-year period are $h^{2}=r=0.23$ in the $198 \mathrm{MZ}$ and $h^{2}=2 r=0.68$ in the $171 \mathrm{DZ}$ eligible pairs. Our values of $h^{2}$ are 0.42 and 0.35 , respectively, for the two zygosity groups (Table 6). Jarvik et al.'s higher concordance rate for $D Z$ than for $M Z$ twins suggests especially strong environmental effects in the DZ group. The institutional nature of that sample probably tends to exaggerate concordance. On the other hand, the $90 \%$ lower confidence limit on $h^{2}$ for the DZ twins is 0.19 , and the high DZ values observed may only be due to sampling variation. Obviously, more long-term follow-up of large samples of twins is desirable. In our sample much of the genetic determination of mortality is yet to exert its effect. Nevertheless, this and the other twin mortality studies make clear that, in the time periods and populations that they represent, environmental factors are at least as important as genetic ones in determining life span and overall mortality.

Acknowledgements. The NAS-NRC Twin Registry is an activity of the Medical Follow-up Agency in the Assembly of Life Sciences, NRC. The Agency is responsible for a program of studies reviewed by the Com- mittee on Epidemiology and Veterans Follow-up Studies and carried out in cooperation with the Veterans Administration, the Department of Defense, and the National Institutes of Health.

The operation of the Twin Registry depends on the records of the Department of Defense, the Veterans Administration, and the National Archives and Records Service of the General Services Administration. The authors are indebted to these organizations for the ready access they provided to the required materials. The use of their records is acknowledged, but it is not to be construed as implying official approval by them of the conclusions presented. The work was supported through a contract with the National Heart, Lung, and Blood Institute (NO1-HV53010) that provides support for the Registry and a contract with the National Institutes of Health Research Contracts Branch (N01-OD-52138).

Miss Hatsumi Hamamura is responsible for managing the activities of the Twin Registry, Mrs. Vivian Farley supervised medical coding, Ms. Marcia L. Egge coordinated data processing, and Mr. Thomas Preston coordinated project activities. We are grateful to Dr. Grace Wyshak for providing a special analysis of her data on twin deaths under 60 years of age.

\section{References}

Allen G (1979) Holzinger's $H_{C}$ revised. Acta Genet Med Gemellol 28 $161-164$

Beebe GW, Simon AH (1969) Ascertainment of mortality in the US veteran population. Am J Epidemiol 89:636-643

Behrman JR, Hrubec Z, Taubman P, Wales TJ (1980) Socioeconomic success. A study of the effects of genetic endowments, family environment, and schooling. North-Holland Publishing Company, Amsterdam New York Oxford

Bulmer MG (1970) The biology of twinning in man. Clarendon Press, Oxford, pp 68-94

Cederlof R, Floderus B. Friberg L (1970) Cancer in MZ and DZ twins. Acta Genet Med Gemellol 19:69-74

Cederlof R, Friberg L, Jonsson E, Kaij L (1961) Studies on similarity diagnosis in twins with the aid of mailed questionnaires. Acta Genet $11: 338-362$

Cederlof R, Lorich U (1978) The Swedish twin registry. In: Nance WE (ed) Twin research, part B: Biology and epidemiology. Alan R Liss, Inc, New York, pp 189-195

Dublin LI, Lotka AF, Spiegelman M (1949) Length of life. The Ronald Press Company, New York

Edwards JH (1969) Familial predisposition in man. Br Med Bull 25: $58-64$

Falconer DS (1965) The inheritance of liability to certain diseases estimated from the incidence among relatives. Ann Hum Genet 29: $51-76$

Finch CE, Hayflick L (eds) (1977) Handbook of the biology of aging. Van Norstand Rheinhold Company, New York

Haldane JBS (1955-56) The estimation and significance of the logarithm of a ratio of frequencies. Ann Hum Genet 20:309-311

Harvald B, Hauge M (1965) Hereditary factors elucidated by twin studies. In: Neel JV, Shaw MW, Schull WJ (eds) Genetics and the epidemiology of chronic disease. PHS Publication No 1163, US Government Printing Office, Washington, DC, pp 61-76

Hauge M, Harvald B, Fischer M, Gotlieb-Jensen K, Juel-Nielsen N, Raebild I, Shapiro R, Videbech T (1968) The Danish twin register. Acta Genet Med Gemellol 17:315-332

Holm NV, Hauge M, Harvald B (1980) Etiologic factors of breast cancer elucidated by a study of unselected twins. J Natl Cancer Inst 65: 285-298

Hrubec Z, Allen G (1975) Methods and interpretation of twin concordance data (Letter to the editor). Am J Hum Genet 27:808-809

Hrubec Z, Neel JV (1978) The National Academy of Sciences-National Research Council Twin Registry: Ten years of operation. In: Nance WE (ed) Twin research, part B: Biology and epidemiology. Alan R Liss, Inc, New York, pp 153-172

Jablon S, Neel JV, Gershowitz H, Atkinson GF (1967) The NAS-NRC twin panel: Methods of construction of the panel, zygosity diagnosis, and proposed use. Am J Hum Genet 19:133-161 
Jarvik LF, Falek A, Kallmann FJ, Lorge I (1960) Survival trends in a senescent twin population. Am J Hum Genet 12:170-179

Kaprio J, Sarna S, Koskenvuo M, Rantasalo I (1978) The Finnish twin registry: Formation and compilation, questionnaire study, zygosity determination procedures, and research program. In: Nance WE (ed) Twin research, part B: Biology and epidemiology. Alan R Liss, Inc, New York, pp 179-184

Kringlen E (1978) Norwegian twin registers. In: Nance WE (ed) Twin research, part B: Biology and epidemiology. Alan R Liss, Inc, New York, pp 185-187

Myers GC, Pitts AM (1977) Alternative projections of the US male veteran population 1970-2000. Working paper from Center for Demographic Studies, Duke University, July 1976, for report by National Research Council, Health care for American veterans. National Academy of Sciences, Washington, DC

Schneider EL (ed) (1978) The genetics of aging. Plenum Press, New York Seltzer CC, Jablon S (1974) Effects of selection on mortality. Am J Epidemiol 100:367-372

Simms HS, Berg BN, Davies DF (1959) Onset of disease and the longevity of rat and man. In: Wolstenholme GEW, O'Connor M (eds) Ciba Foundation colloquia on ageing, vol 5: The lifespan of animals. Little, Brown and Company, Boston, pp 72-89

Smith C (1974) Concordance in twins: Methods and interpretation. Am J Hum Genet 26:454-466

Torgersen S (1979) The determination of twin zygosity by means of a mailed questionnaire. Acta Genet Med Gemellol 28:225-236

US Department of Health, Education, and Welfare (1968) Eighth revision international classification of diseases, adapted for use in the United States. PHS Publication No 1693, US Government Printing Office, Washington, DC

Vogel F, Motulsky AG (1979) Human genetics. Problems and approaches. Springer-Verlag, Berlin Heidelberg New York, pp 586-590

Wyshak G (1978) Fertility and longevity in twins, sibs, and parents of twins. Soc Biol 25:315-330

Wyshak G (1981) Personal communication, March 3, 1981

Received March 24, 1981 